OPEN ACCESS

Edited by:

Pietro Giusti,

University of Padova,

Italy

Reviewed by:

Kalliopi Pitarokoili,

Ruhr University Bochum,

Germany

Alexander A. Sosunov, Columbia University,

United States

${ }^{*}$ Correspondence:

Maryna Skok

skok@biochem.kiev.ua

Specialty section:

This article was submitted to

Neuropharmacology,

a section of the journal

Frontiers in Pharmacology

Received: 14 January 2019

Accepted: 21 March 2019

Published: 17 April 2019

Citation:

Lykhmus O, Koval L, Voytenko L,

Uspenska K, Komisarenko S,

Deryabina O, Shuvalova N, Kordium V,

Ustymenko A, Kyryk V and Skok M

(2019) Intravenously Injected

Mesenchymal Stem Cells Penetrate

the Brain and Treat Inflammation-

Induced Brain Damage and Memory Impairment in Mice.

Front. Pharmacol. 10:355.

doi: 10.3389/fphar.2019.00355

\section{Intravenously Injected Mesenchymal Stem Cells Penetrate the Brain and Treat Inflammation-Induced Brain Damage and Memory Impairment in Mice}

Olena Lykhmus', Lyudmyla Koval', Larysa Voytenko', Kateryna Uspenska', Serhiy Komisarenko ${ }^{1}$, Olena Deryabina ${ }^{2}$, Nadia Shuvalova ${ }^{2}$, Vitalii Kordium ${ }^{2,3}$, Alina Ustymenko ${ }^{2}$, Vitalii Kyryk ${ }^{2}$ and Maryna Skok ${ }^{1 *}$

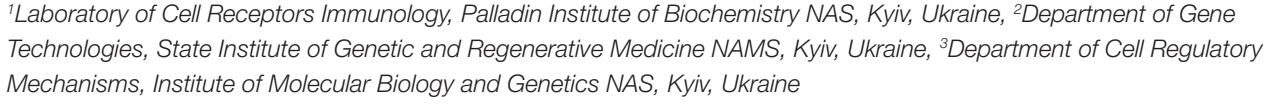
Technologies, State Institute of Genetic and Regenerative Medicine NAMS, Kyiv, Ukraine, ${ }^{3}$ Department of Cell Regulatory Mechanisms, Institute of Molecular Biology and Genetics NAS, Kyiv, Ukraine

Neuroinflammation is regarded as one of the pathogenic factors of Alzheimer disease (AD). Previously, we showed that mice regularly injected with bacterial lipopolysaccharide (LPS) possessed the AD-like symptoms like episodic memory decline, elevated amounts of amyloid beta $(A \beta)$ peptide (1-42), and decreased levels of nicotinic acetylcholine receptors (nAChRs) in the brain. The use of mesenchymal stem cells (MSCs), which can differentiate into multiple cell types, including neurons, is an attractive idea of regenerative medicine, in particular, for neurodegenerative disorders like AD. In the present study, we aimed to investigate whether pathogenic effect of LPS on the brain and behavior of mice can be prevented or treated by injection of MSCs or MSC-produced soluble factors. Fluorescently-labeled MSCs, injected intravenously, were found in the brain blood vessels of LPS-treated mice. Mice co-injected with LPS and MSCs did not demonstrate episodic memory impairment, $A \beta(1-42)$ accumulation, and $n A C h R$ decrease in the brain and brain mitochondria. Their mitochondria released less cytochrome $c$ under the effect of $\mathrm{Ca}^{2+}$ compared to mitochondria of LPS-only-treated mice. Moreover, MSCs could reverse the pathogenic symptoms developed 3 weeks after LPS injection. Cultured MSCs produced IL-6 in response to LPS and MSCs effect in vivo was accompanied by additional stimulation of both micro- and macroglia. Xenogeneic (human) MSCs were almost as efficient as allogeneic (mouse) ones and regular injections of human MSC-conditioned medium also produced positive effect. These data allow suggesting MSCs as a potential therapeutic tool to cure neuroinflammation-related cognitive pathology.

Keywords: neuroinflammation, mesenchymal stem cells, nicotinic acetylcholine receptor, episodic memory, mitochondria, Alzheimer disease 


\section{INTRODUCTION}

Alzheimer disease (AD) is an age-dependent neurodegenerative disorder resulting in impairment of memory, speech, and practical habits. The brains of $\mathrm{AD}$ patients are characterized by cholinergic deficiency and accumulation of extracellular senile plaques formed by oligomerized amyloid beta $(A \beta)$ peptides. $\mathrm{AD}$ is accompanied by inflammatory reactions; moreover, neuroinflammation often precedes the development of cognitive symptoms and may be regarded as one of the pathogenic factors causing neurodegeneration (reviewed in Skok and Lykhmus, 2016).

Cholinergic deficiency is manifested as the decrease of acetylcholine content in the brain due to decreased activity of choline acetyltransferase and the loss of nicotinic acetylcholine receptors (nAChRs) in the cognitively important brain areas leading to degeneration of cholinergic neurons (Keverne and Ray, 2005). Consequently, the use of either acetylcholine esterase (AChE) inhibitors or selective agonists of certain nAChR subtypes aimed to enhance cholinergic signaling has been suggested as a current medication for symptomatic treatment of AD patients (Russo et al., 2014).

The nAChRs are ligand-gated ion channels composed of various combinations of $\alpha(\alpha 1-\alpha 10)$ and $\beta(\beta 1-\beta 4)$ subunits (reviewed in Changeux, 2012). The two main nAChR subtypes found in the brain are $\alpha 7$ and $\alpha 4 \beta 2$ (Champtiaux and Changeux, 2002; Dineley et al., 2015) and both of them are related to AD pathogenesis (Wevers et al., 1999; Guan et al., 2000; Gotti et al., 2006; Posadas et al., 2013). The $\alpha 4 \beta 2$ nAChR signaling underlies the pro-cognitive effects of nicotine (Picciotto et al., 2001), the absence of $\alpha 4 \beta 2 \mathrm{nAChRs}$ in knockout mice favors neurodegeneration upon ageing (Zoli et al., 1999), and the density of $\alpha 4 \beta 2$ nAChRs is decreased in people with neurodegenerative diseases including the $\mathrm{AD}$ (Wevers et al., 1999; Guan et al., 2000). The a7 nAChRs directly interact with $A \beta$ to affect its proper metabolism (Wang et al., 2000; Parri and Dineley, 2010). This nAChR subtype is expressed in both the plasma membrane and mitochondria of the brain cells to support their viability (Parada et al., 2010; Gergalova et al., 2012; Lykhmus et al., 2014). In addition, the a7 $\mathrm{nAChRs}$ expressed in the glial cells regulate inflammatory reactions in the brain (Suzuki et al., 2006; Tyagi et al., 2010; Thomsen and Mikkelsen, 2012).

In our previous studies, we showed that mice regularly injected with bacterial lipopolysaccharide (LPS) possessed decreased levels of $\alpha 7$ and $\alpha 4 \beta 2 \mathrm{nAChRs,} \mathrm{elevated} \mathrm{amounts}$ of $A \beta(1-42)$ in the brain, and demonstrated episodic memory decline (Lykhmus et al., 2015b, 2017). The LPS treatment stimulated astrocytosis in the cortex and striatum and evidently decreased the number of cells in the hippocampus and striatum. The brain mitochondria of LPS-treated mice also contained less $\alpha 7$ nAChRs, more $A \beta$ peptides (1-40) and (1-42) and released more cytochrome $c$ (cyt $c$ ) in response to apoptogenic

\footnotetext{
Abbreviations: AD, Alzheimer disease; cyt $c$, cytochrome $c$; GFP, green fluorescence protein; LPS, lipopolysaccharide; MSCs, mesenchymal stem cells; nAChR, nicotinic acetylcholine receptor.
}

doses of $\mathrm{Ca}^{2+}$. These data allowed us to suggest that neuroinflammation caused by external inflammatory stimuli led to $\alpha 7 \mathrm{nAChR}$ down-regulation, accumulation of $\mathrm{A} \beta$ (1-42), and mitochondria impairment resulting in memory decline and finally neurodegeneration.

Mesenchymal stem cells (MSCs) are self-renewing multipotent cells able to differentiate into multiple cell types including neurons (NIH Stem Cell Information Home Page, 2016). In addition, MSCs produce numerous trophic and growth factors affecting neurogenesis, synaptogenesis, astrocytosis and cell survival (Konala et al., 2016). The efficiency of regenerative MSC therapy has been studied in many experimental models (Kariminekoo et al., 2016) including transgenic mice bearing AD-related mutations (Yang et al., 2013; Chang et al., 2014; Shin et al., 2014) and their role in modulating inflammation (Klinker and Wei, 2015; Zachar et al., 2016) have been demonstrated. In addition, the regenerative potential of MSC-secreted factors vs. the cells per se is being widely discussed (Konala et al., 2016).

In the present study, we put an aim to investigate whether pathogenic effect of LPS on the brain and behavior of mice can be prevented or reversed by MSCs, and if yes, whether the effect can be reproduced by MSC-produced soluble factors.

\section{MATERIALS AND METHODS}

\section{Materials}

All reagents were of chemical grade and purchased from Sigma-Aldrich (Saint Louis, USA), unless specially indicated. Antibodies against $\alpha 3(181-192), \alpha 4(181-192), \alpha 7(179-190)$, $\alpha 9(11-23), \beta 2(190-200)$ or $\beta 4(190-200)$ nAChR fragments and rabbit cyt $c$-specific antibodies were generated using methods previously developed in our lab (Skok et al., 1999; Koval et al., 2004, 2011; Lykhmus et al., 2010; Gergalova et al., 2014). The antibodies were biotinylated according to standard procedures (Harlow and Lane, 1988). Antibodies against $\mathrm{A} \beta$ (1-42), ionized calcium binding adaptor molecule 1 [(Iba-1) or allograft inflammatory factor (AIF-1)] and neutravidin-peroxidase conjugate were purchased from ALT Ukraine Ltd (representing Thermo Fisher Scientific in Ukraine). Rabbit polyclonal antibody against glial fibrillary acidic protein (GFAP) was from Dako (Agilent Technologies); goat antirabbit IgG Alexa 488-labeled and IL-6-specific antibody pair were from Invitrogen.

\section{Animals}

As MSCs recipients, we used C57BL/6 J female mice 3-5 months of age. Placental MSCs were obtained from 6 week-old female FVB wild-type pregnant mice, and GFP-labeled MSCs were obtained from FVB-Cg-Tg (GFPU) 5Nagy/J mice, transgenic by green fluorescent protein (GFP) gene. Mice were kept in the animal facilities of either Palladin Institute of Biochemistry NAS of Ukraine or Dmitry F. Chebotarev Institute of Gerontology NAMS of Ukraine in Kyiv. Mice were housed in quiet, temperature-controlled rooms, and provided with water and food pellets ad libitum. Before removing the brains, mice were 
sacrificed by cervical dislocation. All procedures complied with the ARRIVE guidelines, were carried out in accordance with the Directive 2010/63/EU for animal experiments and were approved by the Animal Care and Use Committee of Palladin Institute of Biochemistry.

\section{Mesenchymal Stem Cells Isolation, Propagation, and Characterization}

Human MSCs (hMSCs) were obtained from Wharton jelly (WJ) using the explant method (Maslova et al., 2013; Shuvalova and Kordium, 2016). Umbilical cords were collected from healthy donors (39-40 weeks of gestation) after their consent. The umbilical cord fragment $(5-10 \mathrm{~cm})$ was washed with PBS, the vessels were mechanically removed. WJ was cut into $0.4-0.5 \mathrm{~mm}$ pieces that were placed in the $75 \mathrm{~cm}^{2}$ cultural flasks containing complete growth medium a-MEM (BioWest, Austria) supplemented with 10\% fetal bovine serum (Invitogen), penicillin $100 \mathrm{U} / \mathrm{ml}$ (Arterium, Ukraine), and streptomycin $100 \mu \mathrm{g} / \mathrm{ml}$ (Arterium, Ukraine). Cultivation was performed under conditions of humidified air with $5 \% \mathrm{CO}_{2}$ at $37^{\circ} \mathrm{C}$. The medium was changed every $4-5$ days. The first attached cells were visible on the 7-10th day. After 14 days the clones reached the size and confluence (70-80\%) sufficient for passing, which was performed by standard method with the use of trypsinEDTA mixture (Shuvalova et al., 2013). The surface marker proteins CD34, CD45, CD90, CD73, CD105 expression was determined at the second passage by flow cytometry (BD FACS Aria) with FITC- and PE- conjugated antibodies (UsBiological, USA) according to minimal criteria for defining multipotent mesenchymal stromal cells (Dominici et al., 2006). The cells of the second passage were used for both in vitro assays and transplantation into LPS-treated mice.

Murine placental multipotent mesenchymal stem cells (mMMSCs, further mMSCs) were obtained from FVB-Cg-Tg (GFPU) 5Nagy/J mice 19th day of pregnancy. Under sterile conditions, placentae were transferred into a Petri dish with cold PBS, containing antibiotics. Fetal membranes were minced and incubated with $0.1 \%$ collagenase type I (Sigma-Aldrich, USA) for $90 \mathrm{~min}$ at $37^{\circ} \mathrm{C}$. Cell pellet obtained after digestion and filtration was washed and seeded in $75 \mathrm{~cm}^{2}$ flasks containing culture medium DMEM-LG (Low Glucose, $1 \mathrm{~g} / \mathrm{L}$ ) supplemented with $10 \%$ fetal bovine serum, penicillin $100 \mathrm{U} / \mathrm{ml}$, streptomycin $100 \mu \mathrm{g} / \mathrm{ml}$ and 1:100 nonessential amino acids (Sigma-Aldrich, USA). Cultivation was carried out in $\mathrm{CO}_{2}$-incubator under conditions of humidified air with $5 \% \mathrm{CO}_{2}$ at $37^{\circ} \mathrm{C}$. The medium was changed every 3-4 days. After approximately 14 days, the cells were rinsed with Dulbecco's Phosphate Buffered Saline (Sigma-Aldrich, USA), and then exposed to pre-warmed trypsinEDTA (0.25\% trypsin, $4 \mathrm{mM}$ EDTA, Invitrogen) for $2 \mathrm{~min}$. The resulting detached cells were resuspended in serumsupplemented medium, counted and seeded as first passage cultures at 4,000 cells per $\mathrm{cm}^{2}$. Subcultivation was performed at $80 \%$ confluence of the monolayer. Cells of the second passage were used in the experiment (Fhilho and Oliveira, 2012).

Phenotyping of cells for markers CD34, CD44, CD45, CD73, CD90, CD105 was performed using fluorochrome-labeled monoclonal antibodies to mouse membrane antigens by flow cytometry. Obtained cell cultures satisfied criteria of MMSCs by phenotype and ability to directed multilinear differentiation.

\section{In vitro Assays}

Mouse MSCs $\left(4 \times 10^{4}\right.$ cells per well $)$ were seeded in 96-well tissue culture plates containing complete growth medium DMEM/F12 supplemented with $10 \%$ fetal bovine serum, penicillin $100 \mathrm{U} / \mathrm{ml}$, streptomycin $100 \mu \mathrm{g} / \mathrm{ml}$ (all-Sigma-Aldrich, USA) and were cultured in the presence of different doses of LPS at $37^{\circ} \mathrm{C}$ and $5 \% \mathrm{CO}_{2}$ during $72 \mathrm{~h}$. Then, the cell supernatant was collected and the cells' quantity/viability was studied in MTT test (Carmichael et al., 1987). The supernatants were tested for the presence of IL-6 using the Murine IL-6 ELI-Pair kit from Diaclone (Gen-Probe, France), according to manufacturer's instructions.

\section{Animal Treatment and Brain Preparations}

In the first set of experiments, three groups of $\mathrm{C} 57 \mathrm{Bl} / 6$ mice, eight animals per group, were intraperitoneally injected with $2 \mathrm{mg} \mathrm{kg}^{-1}$ LPS (E. coli strain 055:B5) in $0.1 \mathrm{ml}$ of saline. Two of these groups, in addition, obtained intravenously, in the tail vein, $10^{6}$ mMSCs or hMSCs in $0.1 \mathrm{ml}$ of incubation medium. Three weeks thereafter, mice were examined in behavioral novel object recognition test, sacrificed and their brains were removed for examination.

In the second set of experiments, three groups of mice, five animals in each, were injected with LPS as described above. After 3 weeks, the mice were examined in behavioral test and one group obtained hMSCs $\left(10^{6}\right.$ in the tail vein), while another group was injected intraperitoneally with $0.3 \mathrm{ml}$ of hMSCconditioned medium obtained after 2 days of cells incubation in serum-free medium. Injections of conditioned medium were repeated every 7 days for 3 weeks more and mice were examined in behavioral test every week. In a month, a week after the last conditioned medium injection, mice were sacrificed and their brains were removed for examination.

To study if intravenously introduced MSC penetrate into the brain parenchyma, GFP-labeled mMSCs $\left(10^{6}\right.$ per animal $)$ were injected into two mice pre-injected with LPS a day before. Mice were sacrificed 24 and $72 \mathrm{~h}$ thereafter and their brains were removed for examination.

For sandwich ELISA experiments and mitochondria examination, the mouse brains were homogenized in a glass homogenizer. The homogenate was fractionated into mitochondria and non-mitochondria by standard procedure of differential centrifugation (Gergalova et al., 2012; Lykhmus et al., 2015a). The purity of fractions obtained was evaluated by ELISA using the antibodies against different cellular compartments, as described previously (Uspenska et al., 2017). Live mitochondria were further examined in functional test of cytochrome c (cyt $c$ ) release (see below), while the pellets of both mitochondria and non-mitochondria fractions were used to prepare the detergent lysates, as described previously (Lykhmus et al., 2015b). Protein concentration was measured with the BCA kit (Thermo Scientific, France).

For immunohistochemistry studies, the brains were fixed in $4 \%$ paraformaldehyde for $48 \mathrm{~h}$, washed in PBS, dehydrated 
with increasing concentrations of alcohol and embedded in ParaplastX-TRA (McCormick Scientific LLC). The paraplastembedded specimens were cut into serial frontal $5 \mu \mathrm{M}$ sections with rotational microtome (HM 325, MICROM International $\mathrm{GmbH})$. The sections were placed onto adhesive microscopic slides to be further examined by immunohistochemistry.

To study MSC penetration into the brain, the brains were fixed in $4 \%$ paraformaldehyde and cut by vibratome into coronal $40 \mu \mathrm{m}$ sections. The floated sections were placed onto microscopic slides to be examined by confocal microscopy.

\section{ELISA Assays}

To determine the level of various nAChR subunits within the brain or mitochondria preparations, the immunoplates (Nunc, Maxisorp) were coated with rabbit $\alpha 7(1-208)$-specific antibody $(20 \mu \mathrm{g} / \mathrm{ml})$, blocked with $1 \% \mathrm{BSA}$, and the detergent lysates of brain tissue or mitochondria were applied into the wells $(1 \mu \mathrm{g}$ of protein per $0.05 \mathrm{ml}$ per well) for $2 \mathrm{~h}$ at $37^{\circ} \mathrm{C}$. The plates were washed with water and the second biotinylated $\alpha 3(181-192)-, \quad \alpha 4(181-192)-, \quad \alpha 7(179-190)-$, $\alpha 9(11-23)-, \beta 2(190-200)$ - or $\beta 4(190-200)$-specific antibody was applied for additional $2 \mathrm{~h}$ being revealed with Neutravidin-peroxidase conjugate and $o$-phenylendiaminecontaining substrate solution.

To determine the level of $A \beta$ (1-42) bound to $\alpha 7 \mathrm{nAChR}$, the plates were coated with $\alpha 7(1-208)$-specific antibody, and the $\alpha 7-A \beta$ complex from the brain or mitochondria preparation applied as described above was revealed with biotinylated $A \beta$ (1-42)-specific antibody, Neutravidin-peroxidase conjugate and $o$-phenylendiamine-containing substrate solution. The optical density was read at $490 \mathrm{~nm}$ using Stat-Fax 2000 ELISA Reader (Awareness Technologies, USA).

\section{Immunohistochemistry and Confocal Microscopy}

Before immunohistochemical staining, the brain sections were de-paraffinated by standard procedure; the nonspecific binding was blocked with $1 \%$ BSA in PBS (30 min, RT). For staining the $A \beta(1-42)$, the slides were incubated with biotinylated mouse $A \beta$ (1-42)-specific antibody (1:200) overnight at room temperature, washed with PBS and incubated with Extravidin-Cy3 $(1,200)$ in $1 \%$ BSA-containing PBS for $1 \mathrm{~h}$ at RT. Nonspecific binding was blocked with goat anti-mouse IgG.

For staining the astrocytes, the slides were incubated with rabbit anti-GFAP antibody (1:100) followed by goat anti-rabbitAlexa 488.

For staining the microglia, the slides were incubated with biotinylated anti-Iba-1 antibody (1:100) followed by Streptavidin-Cy3.

As negative controls, the incubations without primary antibody were performed in both control and experimental sections.

All slides with paraplast sections were embedded in MOWIOL-DABCO, while slides with floated brain sections were embedded in Vectashield and examined under Zeiss LSM 510 Meta confocal lasers canning microscope (Zeiss, Germany). The brain regions were identified according to Paxinos and Franklin, 2001.

\section{Mitochondria Functional Assay}

The purified live mitochondria $(120 \mu \mathrm{g}$ of protein per $\mathrm{ml})$ were incubated with either $0.1 \mu \mathrm{M} \mathrm{CaCl}_{2}$ or $0.9 \mu \mathrm{M} \mathrm{CaCl}_{2}$ for $5 \mathrm{~min}$ at room temperature and were immediately pelleted by centrifugation $(10 \mathrm{~min}, 7,000 \mathrm{~g})$ at $4^{\circ} \mathrm{C}$. The incubation medium contained $10 \mathrm{mM}$ HEPES, $125 \mathrm{mM} \mathrm{KCl,} 25 \mathrm{mM}$ $\mathrm{NaCl}, 5 \mathrm{mM}$ sodium succinate and $0.1 \mathrm{mM} \mathrm{Pi}(\mathrm{K}), \mathrm{pH}$ 7.4. The mitochondria supernatants were collected and tested for the presence of cyt $c$ by sandwich assay as described previously (Gergalova et al., 2012, 2014).

\section{Behavioral Experiments}

Mice of all groups were tested in the "Novel Object Recognition" (NOR) behavioral test (Antunes and Biala, 2012; Lykhmus et al., 2015a,b) prior and post-treatments. Briefly, the animals were individually placed in a rectangular novel open field containing two identical objects with distinctive features (shape and texture). The animals were subjected to a 10-min session of exploration of the objects followed by $10 \mathrm{~min}$ in a waiting cage. During the second 10-min session, one of the objects was replaced by a novel one, and we scored the time spent in contact with each object. It is widely acknowledged that rodents spontaneously explore novel objects by touching the objects with their nose and prefer novel objects to familiar ones that reflect their episodic memory (Save et al., 1992; Thinus-Blanc, 1996). Therefore, the time spent in contact with each object reflects the time of exploration for the object. The results of NOR test are presented as discrimination index (DI) calculated as the difference in the number of "novel" and "famous" object explorations divided by the total number of explorations of two identical objects.

\section{Statistical Analysis}

ELISA experiments have been performed in triplicates and mean values for individual mice were used for statistical analysis assessed using one-way ANOVA test. Behavioral tests were also performed in triplicate for each mouse and mean values for individual mice were taken for statistical analysis. The data are presented as mean $\pm \mathrm{SD} ;{ }^{*} p<0.05 ;{ }^{* *} p<0.005 ;{ }^{* *} p<0.0005$.

\section{RESULTS}

\section{Both Mouse and Human MSCs Prevent Pathogenic Effect of LPS on Mouse Brains and Behavior}

We used MSCs from two sources: either human umbilical cord (hMSCs) or mouse placenta (mMSCs). Both types of cells satisfied minimal criteria for defining multipotent mesenchymal stromal cells according to CD34, CD44, CD45, CD90, CD73, CD105 surface markers expression (Dominici et al., 2006) and were used for transplantation after two passages in vitro. Morphology of mMSCs in primary culture and at the second passage is shown in Figures 1A,B. Both mMSCs and hMSCs were shown to proliferate and to produce IL-6 in response to LPS stimulation (data for mMSCs are shown in Figures 1C,D). 

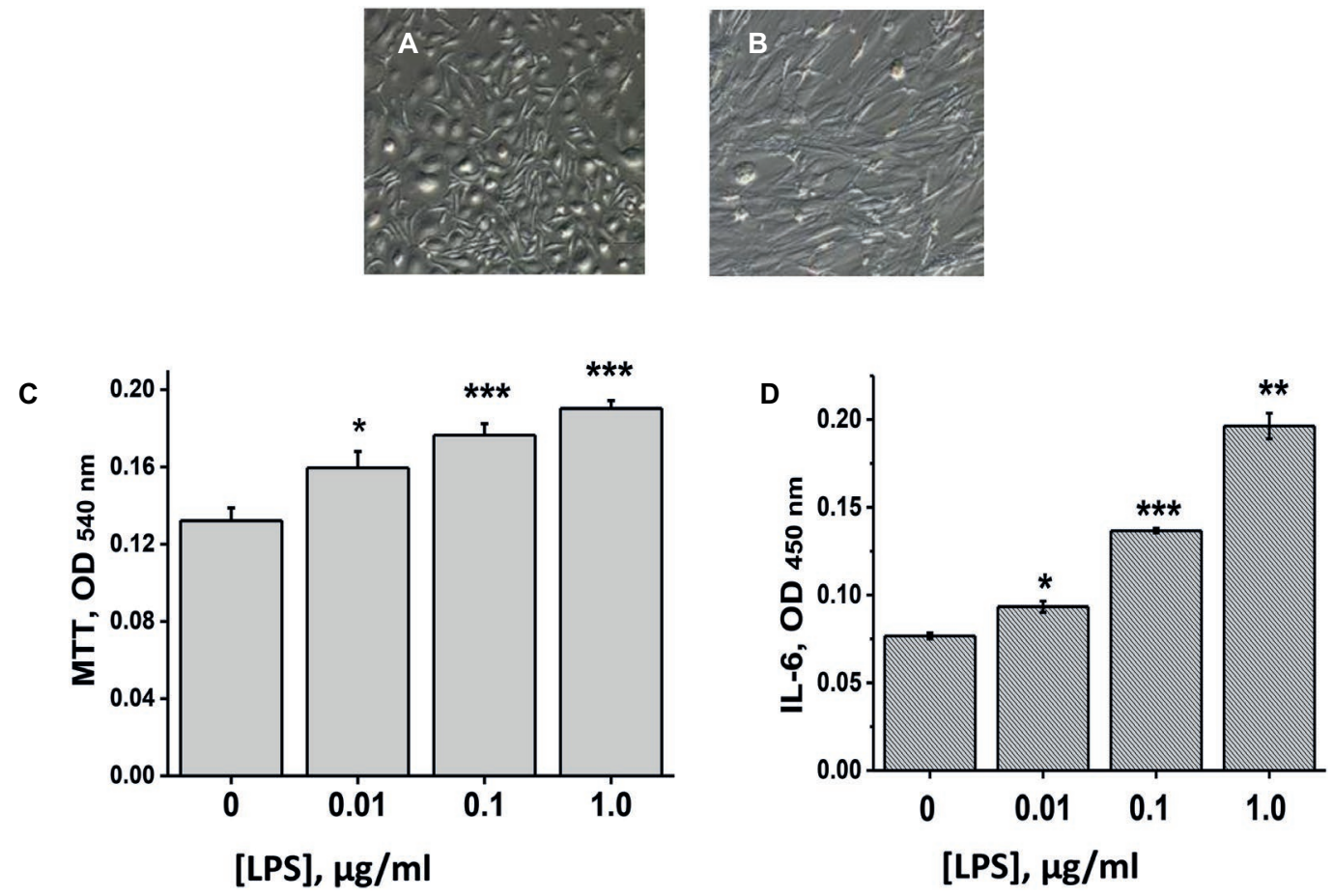

FIGURE 1 | Placental mMSCs cultured in vitro. (A,B) - microscopic images of primary (A) and passage 2 cells (B); their proliferation (MTT test) (C), and IL-6 production (D) under the effect of LPS. Each column in $\mathrm{C}$ and D corresponds to $\mathrm{M} \pm \mathrm{SD}$ of triplicate measurements; ${ }^{*} p<0.05 ;{ }^{* *} p<0.005 ;{ }^{* \star *} p<0.0005$ compared to Ctrl (no LPS).

In the first set of experiments, mice were injected intraperitoneally with LPS and intravenously with either hMSCs or mMSCs $\left(10^{6}\right.$ cells per mouse) at the same time. Three weeks later, they were examined in memory test and their brains and brain mitochondria were studied for the levels of a7 nAChR, $\mathrm{A} \beta(1-42)$ and cyt $c$ released upon $\mathrm{Ca}^{2+}$ stimulation.

It was found that MSCs injection prevented $a 7 \mathrm{nAChR}$ decrease, $A \beta$ (1-42) accumulation and increased cyt $c$ release from mitochondria, as well as episodic memory decline caused by LPS. Human MSCs were almost as efficient as mouse ones in a majority of tests (Figure 2).

The use of GFP-labeled mouse MSCs demonstrated that green fluorescent signal could be found along/around the brain blood vessels 3 days after intravenous injection (Figure 3 ).

\section{Both Human MSCs and Their Conditioned Media Reverse the Pathogenic Effects Developed 3 Weeks After LPS Injection}

The second set of experiments was undertaken to find out whether the MSCs effect is due to cellular or humoral influence and whether it is only prophylactic or can also be therapeutic, i.e., cure the already developed pathogenic symptoms caused by LPS.

For this purpose, mice were injected intravenously with xenogeneic (human) MSCs 3 weeks after LPS injection when memory decline was already observed. Another group of LPS-treated mice was injected once per week intraperitoneally with the conditioned culture medium in which hMSCs were grown to $80 \%$ confluency and were maintained for 2 days without serum. Mice were examined in memory test every week thereafter, then sacrificed and their brains and brain mitochondria were studied as in the previous set of experiments. In this case, we studied a broader range of $\mathrm{nAChR}$ subunits in both the mitochondrial and nonmitochondrial brain fractions. It was found that either hMSCs or their supernatants up-regulated $\alpha 4, \alpha 9$ and $\beta 2 \mathrm{nAChR}$ subunits in their brains (Figure 4A) and brain mitochondria (Figure 4C); MSCs additionally up-regulated $\beta 4$ subunits and decreased the level of $\mathrm{A} \beta$ (1-42) (Figures 4B,D). Either hMSCs or their supernatants also restored memory of LPS-treated mice and significantly improved mitochondria sustainability to $\mathrm{Ca}^{2+}$ (Figures 5A,B). In contrast to MSCs, which supported memory of LPS-treated mice for at least 3 weeks, the effect of a single injection of conditioned medium was transient and disappeared after 2 weeks (Figure $\mathbf{5 A}$ ).

The visible decrease of $A \beta(1-42)$ accumulated in the frontal cortex, striatum and hippocampus of LPS injected mice under the effect of either MSC or their conditioned medium was found by means of immunohistochemistry (Figure 6).

Finally, MSC visibly increased the green signal for GFAP (Figure 7), while their conditioned medium increased Iba-1-specific staining (Figure 8) in the brains of LPS-treated mice. Although no quantitative analysis has been performed in this experiment, the data allow suggesting that the treatments increased the number of activated astrocytes (GFAP) or microglial cells (Iba-1). 

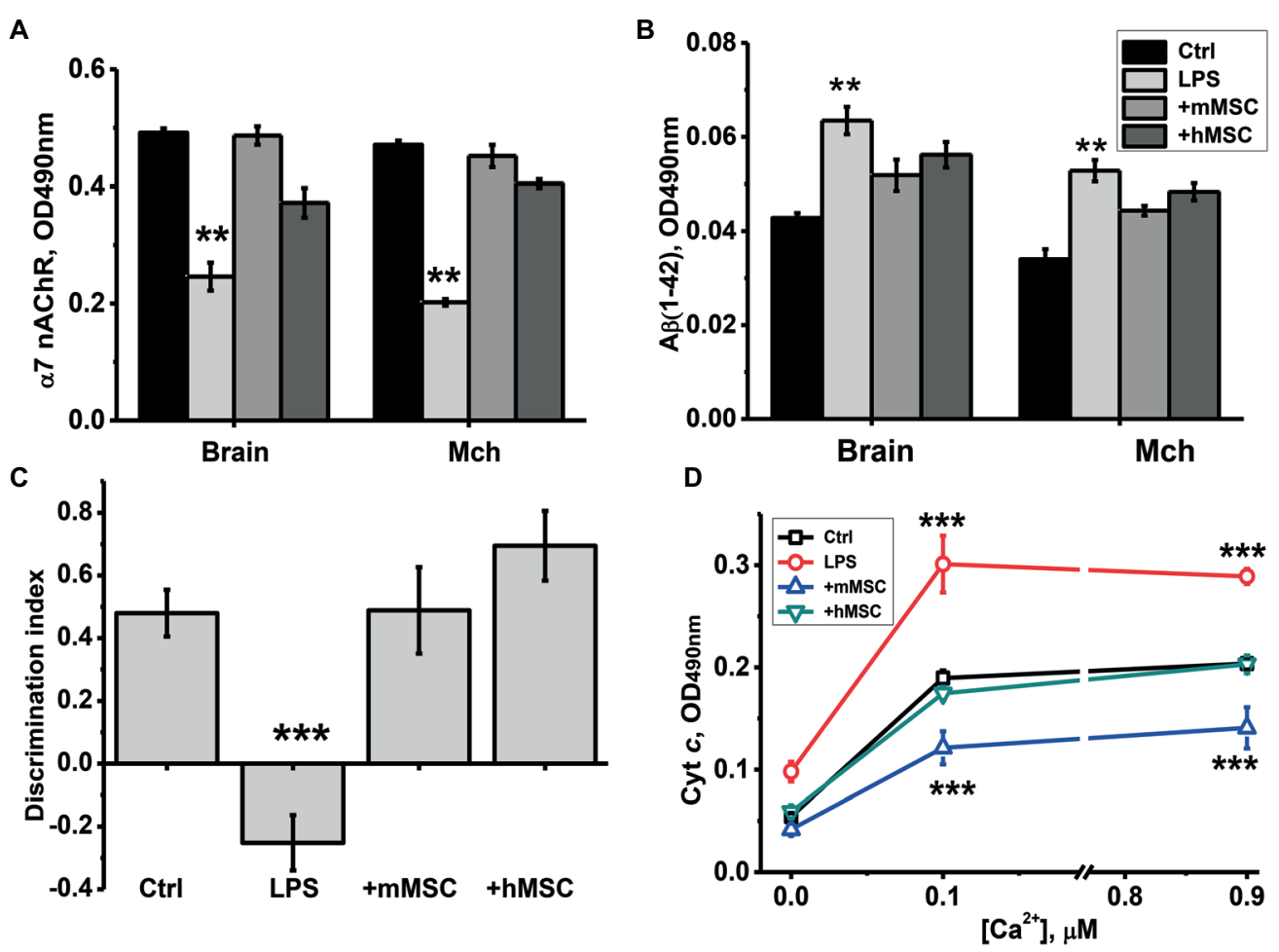

FIGURE 2 | The effect of either hMSCs or mMSCs on $\alpha 7$ nAChR (A) or A $\beta$ (1-42) (B) levels in the brain, memory impairment (C) and cyt $c$ release from the brain mitochondria (Mch) under the effect of $\mathrm{Ca}^{2+}$ (D). Ctrl - samples of non-treated mice. Each column (A-C) or point (D) corresponds to $\mathrm{M} \pm \mathrm{SD}$ of data for separate mice in each group $(n=8) .{ }^{* *} p<0.005 ;{ }^{* \star *} p<0.0005$ compared to Ctrl. Designations of columns are similar in (A) and (B).

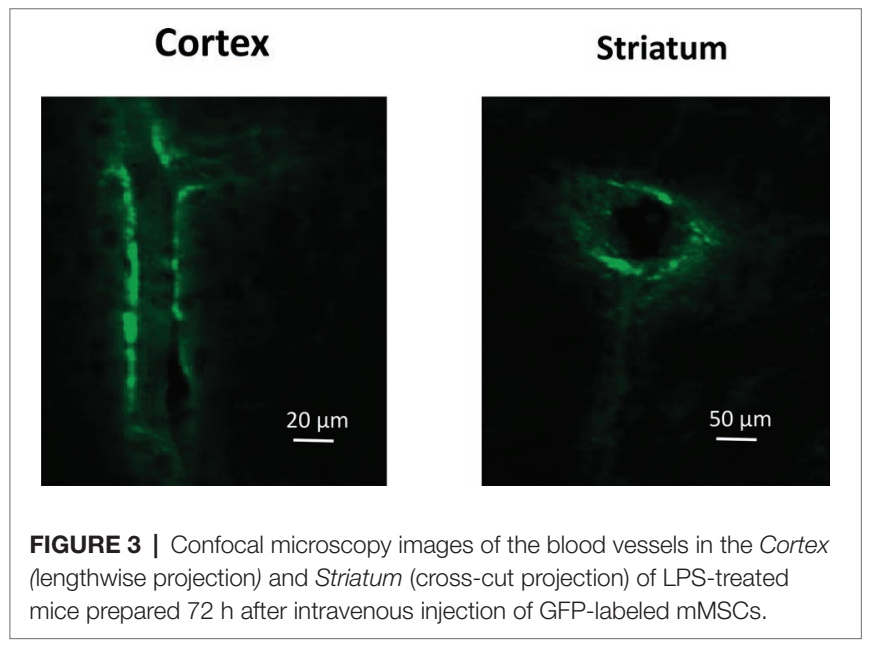

\section{DISCUSSION}

The data obtained in the first set of experiments indicated that MSCs injected intravenously prevent the pathogenic effect of LPS on the brain, brain mitochondria and behavior of LPS-treated mice. In particular, they prevented the a7 nAChR decrease, $A \beta$ (1-42) accumulation, mitochondria and episodic memory impairment caused by LPS injection. Xenogeneic (human) MSCs were almost as efficient as allogeneic (mouse) ones suggesting that their effect was mostly due to soluble growth/trophic factors produced. This suggestion was approved in the second set of experiments where regular injections of hMSC-conditioned medium appeared to be almost as efficient as MSC themselves. In addition, it was found that MSCs can not only prevent the pathogenic effect of LPS, but also reverse the already developed $\mathrm{nAChR}$ decrease, $\mathrm{A} \beta$ (1-42) accumulation, mitochondria, and memory impairment. The anti-LPS effect of MSCs was accompanied by additional stimulation of both micro- and macroglia suggesting that these cells are the targets of MSC-produced soluble factors. We can speculate that positive effect of MSCs is, at least partly, due to activation of trophic functions of glial cells.

The use of multipotent stem cells is an attractive idea of regenerative medicine, in particular, for neurodegenerative disorders like AD. The therapeutic effect of MSCs has been already studied in several AD models. The first studies were performed with the bone-marrow-derived MSCs transplanted intracerebrally (Lee et al., 2009, 2010a,b, 2012; Zhang et al., 2012; Bae et al., 2013) in mice either pre-injected with $A \beta$ (Lee et al., 2009, 2010a) or transgenic for APP/PS1 (Lee et al., 2010b, 2012; Bae et al., 2013). A big piece of studies was performed with human MSCs from adipose tissue, a good source of autologous MSCs (Ma et al., 2013; Chang et al., 2014; Yan et al., 2014). Human umbilical cord MSCs were also transplanted intracerebrally in APP/PS1 mice (Lee et al., 2012; Yang et al., 2013). In all cases, the improvement of 


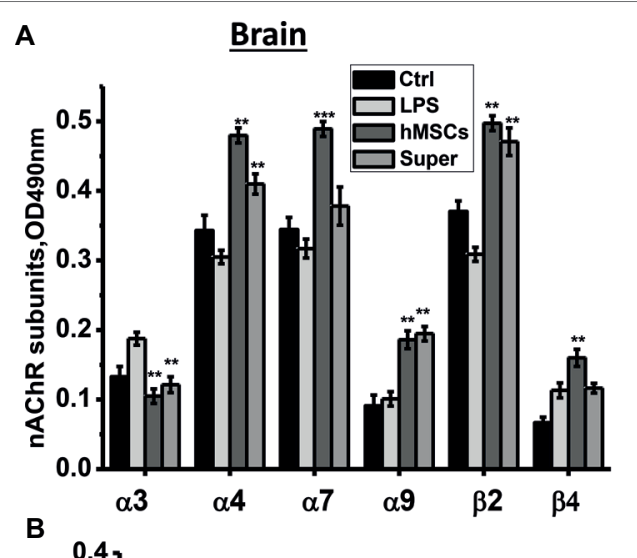

\section{C}

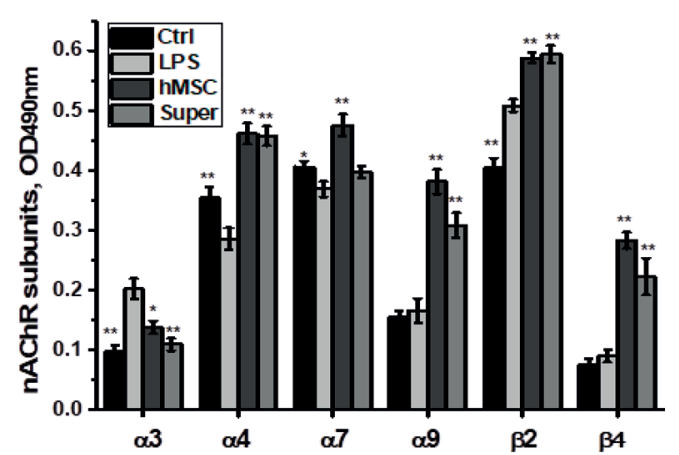

D

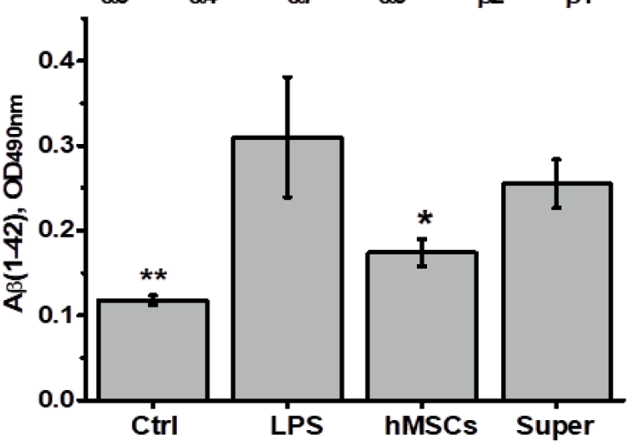

FIGURE 4 | The effects of either hMSCs or their conditioned medium (Super) on the level of nAChR subunits (A,C) or $\alpha 7-$ bound A (1-42) (B,D) in the brain and brain mitochondria of mice pre-injected with LPS 3 weeks before. Each column corresponds to $\mathrm{M} \pm \mathrm{SD}$ of data for separate mice in each group $(n=5){ }^{\star} p<0.05 ;{ }^{\star \star} p<0.005 ;{ }^{\star \star \star} p<0.0005$ compared to LPS-treated samples/mice.
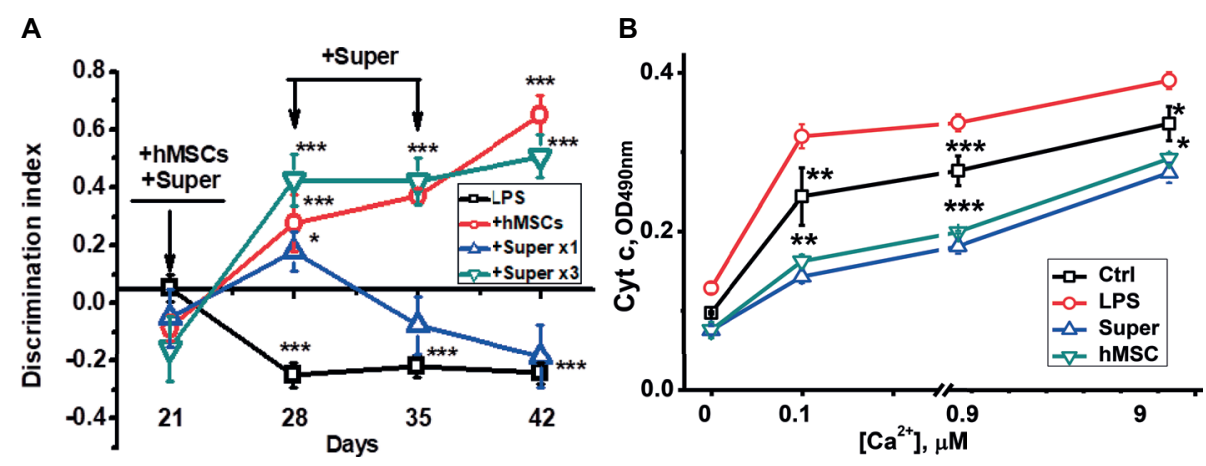

FIGURE 5 | The effects of either hMSCs or their conditioned medium (Super) on episodic memory (A) and cyt $c$ release from the brain mitochondria under the effect of $\mathrm{Ca}^{2+} \mathbf{( B )}$ in mice pre-injected with LPS 3 weeks before. Arrows in (A) indicate the time points of LPS, MSCs or conditioned medium injections. Each point corresponds to $\mathrm{M} \pm \mathrm{SD}$ of data for separate mice in each group $(n=5){ }^{\star} p<0.05 ;{ }^{\star \star} p<0.005 ;{ }^{\star \star \star} p<0.0005$ compared to LPS-treated samples/mice.

cognitive (memory) and synaptic functions, as well as reduced $\mathrm{A} \beta$ deposition has been observed that is in accord with our data. Advantage of our model is that the $A \beta$ accumulation in the brain occurred in a natural way in genetically non-modified mice. The wild-type mice do not form senile plaques; however, significant accumulation of soluble $\mathrm{A} \beta$ could be observed and it was significantly decreased upon MSC injection. Moreover, we show that MSCs can not only prevent the pathogenic effect of LPS, but cure the already developed pathogenic symptoms including memory impairment.
In contrast to the studies cited above, we injected MSCs intravenously. The brain is protected from penetration of peripheral cells by the blood-brain barrier. However, the integrity of the cerebral vasculature is compromised following inflammation (Zlokovic, 2008). In particular, a diminished function of the blood-brain barrier is an early event in multiple sclerosis when inflammation facilitates the massive influx of leukocytes into the brain parenchyma inducing demyelination, tissue damage and axonal disfunction (Kamphuis et al., 2015). Previously, we reported that the blood-brain barrier in 


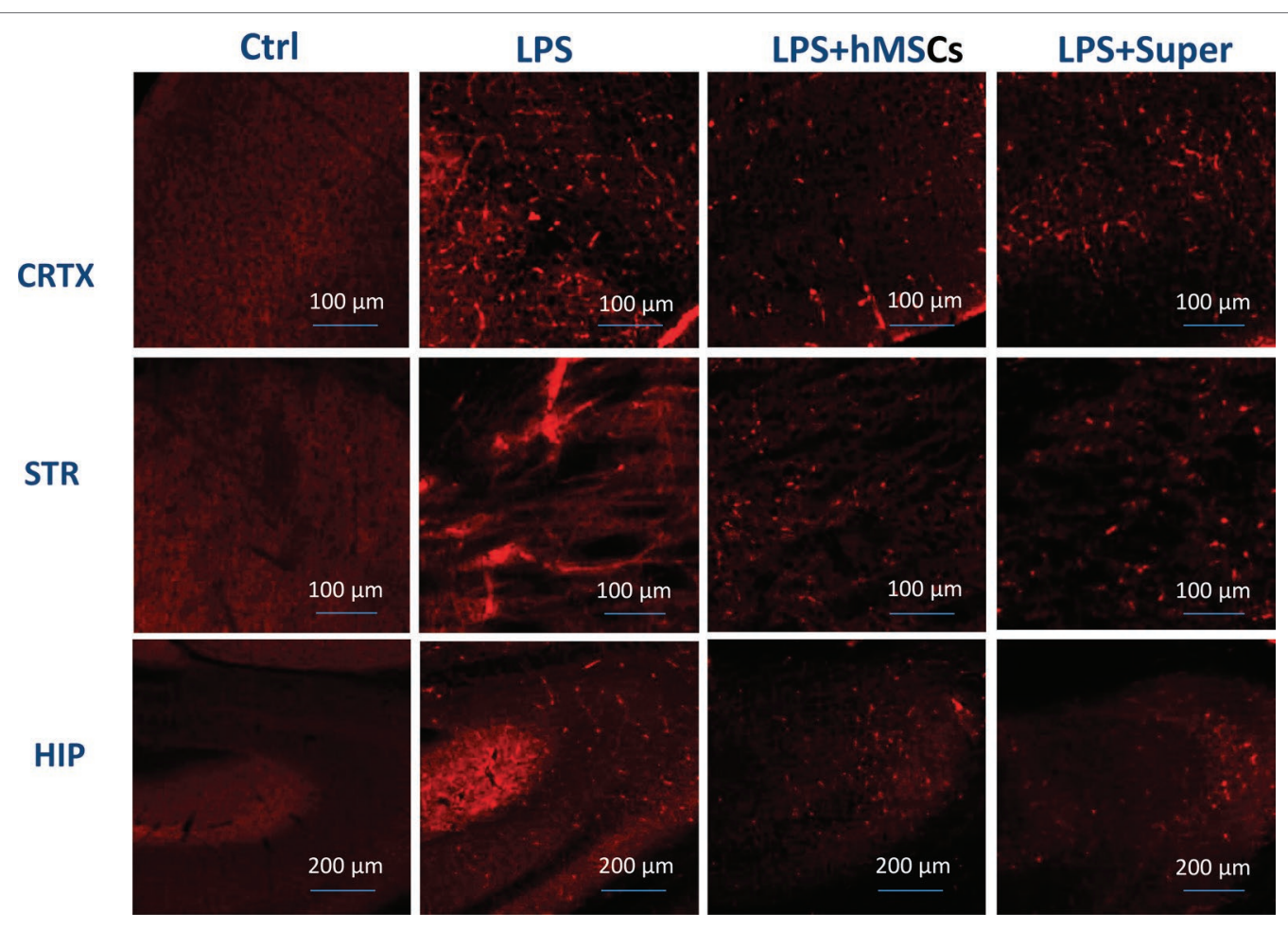

FIGURE 6 | Confocal microscopy images of the brain slices obtained from non-treated (Ctrl), LPS-treated, LPS + hMSCs-treated or LPS + Sup-treated mice and stained with A $\beta$ (1-42)-specific antibody (red). CRTX, cortex; STR, striatum; HIP, hippocampus.

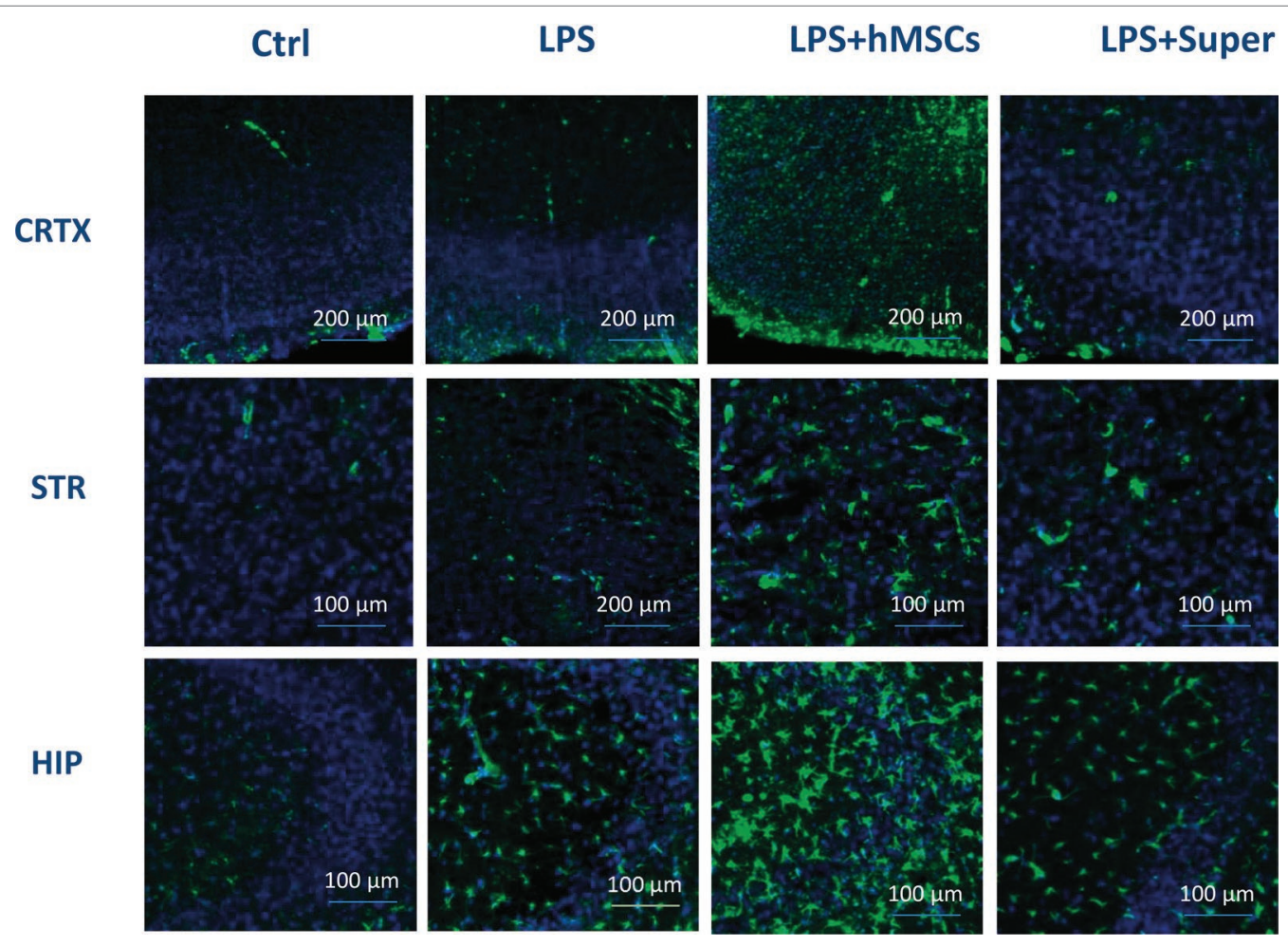

FIGURE 7 | Confocal microscopy images of the brain slices obtained from non-treated (Ctrl), LPS-treated, LPS + hMSCs-treated or LPS + Sup-treated mice and stained with GFAP-specific antibody (green) and DAPI (blue). CRTX, cortex; STR, striatum; HIP, hippocampus. 


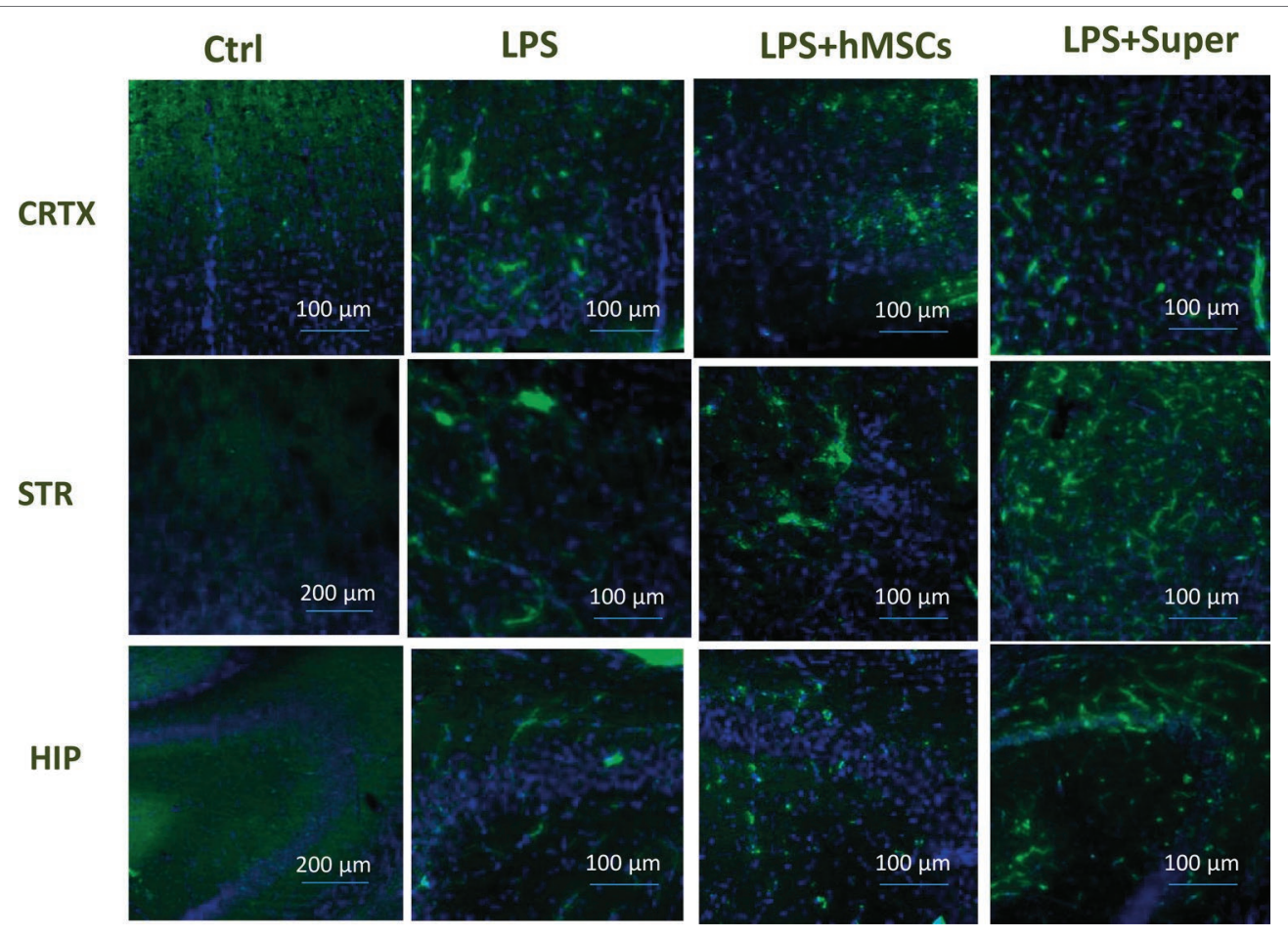

FIGURE 8 | Confocal microscopy images of the brain slices obtained from non-treated (Ctrl), LPS-treated, LPS + hMSCs-treated or LPS + Sup-treated mice and stained with lba-1-specific antibody (green) and DAPI (blue). CRTX, cortex; STR, striatum; HIP, hippocampus.

LPS-treated mice had been disturbed to allow the nAChRspecific antibody penetration (Lykhmus et al., 2015b). Here, we show that MSCs can be found along the brain vessels of LPS-pre-treated mice 3 days after intravenous injection. This is in accord with the data of Lee et al., who found intraarterially injected MSCs in the brain vasculature (Lee et al., 2016). It was also shown that, at least in vitro, MSCs possess leukocytelike molecular mechanisms enabling interaction with vascular endothelial cells (Rüster et al., 2006). Therefore, it is reasonable to expect that MSCs can penetrate the brain parenchyma via transmigration. Indeed, intravenously injected mouse bone marrow cells or human adipose-derived MSCs did cross the blood-brain barrier and migrated into the brain in a rat (Salem et al., 2014) or mouse models for AD (Kim et al., 2012). The $\mathrm{AD}$ pathology in humans is accompanied by elevated pro-inflammatory cytokines, which can affect the integrity of the blood-brain barrier (Zenaro et al., 2017; Toropova et al., 2018). However, whether its damage is comparable to that found upon multiple sclerosis and other autoimmune pathologies of the central nervous system and whether it is sufficient to allow intravenously injected MSC to penetrate the brain parenchyma is a reasonable question which needs to be addressed.

The important fact, not examined in previous studies, is that MSC injection restores/elevates the level of nAChRs in the brain and brain mitochondria decreased as a result of LPS treatment. The MSCs up-regulated $\alpha 4, \alpha 7, \alpha 9, \beta 2$ and $\beta 4$ subunits in the brain and brain mitochondria, while the conditioned medium did not affect $\alpha 7$ subunits decreased by LPS. Both $\alpha 7$ and $\alpha 4 \beta 2$
nAChRs expressed in the brain are involved in regulating cognition and memory (Gotti et al., 2006) and mitochondriaexpressed $\alpha 7 \beta 2$, $\alpha 4 \beta 2$, and $\alpha 9 \mathrm{nAChRs}$ are involved in the anti-apoptotic pathways (Gergalova et al., 2012, 2014; Lykhmus et al., 2014; Uspenska et al., 2018); therefore, their increased levels make mitochondria more resistant to apoptogenic influence and support the viability of brain cells. In one of the published papers, MSCs were introduced together with galantaminecontaining nanoparticles; that was expected to inhibit AChE and increase cholinergic signaling (Misra et al., 2016). Our data indicate that MSCs themselves contribute to cholinergic signaling in the brain by increasing the level of nAChRs.

Another important question arising from positive effects of MSC in AD models is whether they are due to direct involvement of differentiated MSC into neuronal networks in the brain (the true regenerative medicine) or are mediated by numerous trophic and growth factors produced by MSCs to stimulate the host cells. The latter possibility is therapeutically important because it allows avoiding cell transplantation by substituting it with the use of MSC-produced substances. Previous studies demonstrated that human MSCs stimulated neurogenesis both in vitro (Park et al., 2016) and in vivo (Yan et al., 2014; Kim et al., 2015; Oh et al., 2015) by producing soluble factors like activin A, growth differentiation factor-15 and activating Wnt signaling pathway in neuronal progenitor cells. Moreover, it was found that MSCs produce extracellular vesicles (exosomes), which contain neprilysin, enzyme involved in $A \beta$ degradation (Katsuda et al., 2013), and these exosomes can be suggested for AD therapy (Katsuda et al., 2015). 
We show here that supernatants of hMSC culture, applied intraperitoneally, improved memory of LPS-treated mice and affected their brains almost similarly to MSCs. However, in contrast to MSCs, which improved the state of mice for at least 3 weeks after a single injection, the effect of MSC supernatant was transient and regular injections were required to maintain the improvement achieved. Additional studies are required to establish whether MSC-conditioned medium can provide a stable therapeutic effect.

Finally, it is not definitely clear which cells in the brain are the targets for MSC-produced factors. The effects of MSC co-culture with neuronal progenitor cells suggested the direct influence on the brain neurons (Oh et al., 2015; Park et al., 2016). However, other studies demonstrated that intracerebrally transplanted human adipose MSCs activate microglia around senile plaques in the brain of APP/PS1 transgenic mice (Ma et al., 2013). We observed a visible activation of both microglia and astrocytes in the brains of MSC-injected mice, additional to that induced by LPS, and showed that MSCs produce IL-6 in response to LPS stimulation in vitro. Therefore, injecting MSCs simultaneously with LPS could stimulate MSCs for IL-6 production. IL-6 is a pro-inflammatory cytokine, but is also known as a neurotrophic factor (Hirota et al., 1996; Wagner, 1996). Recently, it was reported that mesenchymal progenitor cells derived from induced pluripotent stem cells enhance neuritogenesis via neurotrophin and cytokine (including IL-6) production (Brick et al., 2018). Therefore, IL-6 may be one of neurotrophic soluble factors produced by MSCs penetrating the brain that can affect both neurons and glial cells.

The data obtained put a wider question on what happens in the mouse brain under the effect of injected MSCs. The ability of MSCs to prevent LPS pathogenic effect (simultaneous injection of LPS and MSCs) indicates that MSCs do not allow such effect to develop. However, positive MSCs effect when pathological symptoms have already developed (MSCs injection 3 weeks after LPS) allows suggesting that MSCs, or their soluble factors, directly or indirectly (by activating glial cells) restore the activity of damaged brain neurons. Further experiments

\section{REFERENCES}

Antunes, M., and Biala, G. (2012). The novel object recognition memory: neurobiology, test procedure, and its modifications. Cogn. Process. 13, 93-110. doi: 10.1007/s10339-011-0430-z

Bae, J. S., Jin, H. K., Lee, J. K., Richardson, J. C., and Carter, J. E. (2013). Bone marrow-derived mesenchymal stem cells contribute to the reduction of amyloid- $\beta$ deposits and the improvement of synaptic transmission in a mouse model of pre-dementia Alzheimer's disease. Curr. Alzheimer Res. 10, 524-531. doi: 10.2174/15672050113109990027

Brick, R. M., Sun, A. X., and Tuan, R. S. (2018). Neurotrophically induced mesenchymal progenitor cells derived from induced pluripotent stem cells enhance neuritogenesis via neurotrophin and cytokine production. Stem Cells Transl. Med. 7, 45-58. doi: 10.1002/sctm.17-0108

Carmichael, J., DeGraff, W. G., Gazdar, A. F., Minna, J. D., and Mitchell, J. B. (1987). Evaluation of a tetrazolium-based semiautomated colorimetric assay: assessment of radiosensitivity. Cancer Res. 47, 943-946.

Champtiaux, N., and Changeux, J. P. (2002). Knock-out and knock-in mice to investigate the role of nicotinic receptors in the central nervous system. Curr. Drug Targets CNS Neurol. Disord. 1, 319-330. are needed to reveal whether the recovery observed under the MSCs effect is long-lasting or just temporal.

\section{CONCLUSIONS}

1. Intravenously injected MSCs penetrate the brain of LPS-treated mice.

2. Either allogenic (mouse) or xenogeneic (human) MSCs prevent and reverse the pathogenic effect of LPS on the brain nAChRs, $A \beta$ accumulation, mitochondria and memory impairment.

3. The MSCs therapeutic action is largely due to their humoral factors and is accompanied by activation of microand macroglia.

\section{ETHICS STATEMENT}

This study was carried out in accordance with the recommendation of the guidelines of the Animal Care and Use Committee of Palladin Institute of Biochemistry, Kiev. The protocol was approved by the IACUC of Palladin Institute of Biochemistry.

\section{AUTHOR CONTRIBUTIONS}

MS, OD, SK, OL, and VKo made substantial contributions to the conception or design of the work. LK, OL, LV, KU, MS, $\mathrm{NS}$, and AU contributed to acquisition, analysis, and interpretation of data for the work. MS drafted the work. OD, VKy, and AU revised it critically for important intellectual content. LK, OL, LV, KU, SK, VKo, OD, NS, VKy, and AU finally approved the version to be published. LK, OL, LV, KU, SK, VKo, OD, $\mathrm{NS}, \mathrm{VKy}$, and $\mathrm{AU}$ agreed to be accountable for all aspects of the work in ensuring that questions related to the accuracy or integrity of any part of the work are appropriately investigated and resolved.

Chang, K. A., Kim, H. J., Joo, Y., Ha, S., and Suh, Y. H. (2014). The therapeutic effects of human adipose-derived stemcells in Alzheimer's disease mouse models. Neurodegener. Dis. 13, 99-102. doi: 10.1159/000355261

Changeux, J. P. (2012). Thenicotinic acetylcholine receptor: the founding father of the pentameric ligand-gated ion channel superfamily. J. Biol. Chem. 287, 40207-40215. doi: 10.1074/jbc.R112.407668

Dineley, K. T., Pandya, A. A., and Yakel, J. L. (2015). Nicotinic ACh receptors as therapeutic targets in CNS disorders. Trends Pharmacol. Sci. 36, 96-108. doi: $10.1016 /$ j.tips.2014.12.002

Dominici, M., Le Blanc, K., Mueller, I., Slaper-Cortenbach, I., Marini, F., Krause, D., et al. (2006). Minimal criteria for defining multipotent mesenchymal stromal cells. The International Society for Cellular Therapy position statement. Cytotherapy 8, 315-317. doi: $10.1080 / 14653240600855905$

Fhilho, J. B. B., and Oliveira, M. S. (2012). Placental structure and biological aspects of fetal membranes cultured in vitro. Open access chapter from "Biomedical Tissue Culture". eds. L. Ceccherini-Nelli, and B. Matteoli. doi: $10.5772 / 51274$

Gergalova, G., Lykhmus, O., Komisarenko, S., and Skok, M. (2014). a7 Nicotinic acetylcholine receptors control cytochrome $\mathrm{c}$ release from isolated mitochondria 
through kinase-mediated pathways. Int. J. Biochem. Cell Biol. 49, 26-31. doi: 10.1016/j.biocel.2014.01.001

Gergalova, G. L., Lykhmus, O. Y., Kalashnyk, O. M., Koval, L. M., Chernyshov, V. I., Kryukova, E., et al. (2012). Mitochondria express a7 nicotinic acetylcholine receptors to regulate $\mathrm{Ca}^{2+}$ accumulation and cytochrome $c$ release: study on isolated mitochondria. PLoS One 7:e31361. doi: 10.1371/ journal.pone.0031361

Gotti, C., Zoli, M., and Clementi, F. (2006). Brain nicotinic acetylcholine receptors: native subtypes and their relevance. Trends Pharmacol. Sci. 27, 482-491. doi: 10.1016/j.tips.2006.07.004

Guan, Z., Zhang, X., Ravid, R., and Nordberg, A. (2000). Decreased protein levels of nicotinic receptor subunits in the hippocampus and temporal cortex of patients with Alzheimer's disease. J. Neurochem. 74, 237-243. doi: 10.1046/j. 1471-4159.2000.0740237.x

Harlow, E., and Lane, D. (1988). Antibodies. A laboratory manual. (New York: Cold Spring Harbor Laboratory), 341-342.

Hirota, H., Kiyama, H., Kishimoto, T., and Taga, T. (1996). Accelerated nerve regeneration in mice by upregulated expression of interleukin (IL) 6 and IL-6 receptor after trauma. J. Exp. Med. 183, 2627-2634. doi: 10.1084/jem.183.6.2627

Kamphuis, W. W., Derada Troletti, C., Reijerkerk, A., Romero, I. A., and de Vries, H. E. (2015). The blood-brain barrier in multiple sclerosis: micro RNAs as key regulators. CNS Neurol. Disord. Drug Targets 14, 157-167. doi: $10.2174 / 1871527314666150116125246$

Kariminekoo, S., Movassaghpour, A., Rahimzadeh, A., Talebi, M., Shamsasenjan, K., and Akbarzadeh, A. (2016). Implications of mesenchymal stem cells in regenerative medicine. Artif. Cells Nanomed. Biotechnol. 44, 749-757. doi: 10.3109/21691401.2015.1129620

Katsuda, T., Oki, K., and Ochiya, T. (2015). Potential application of extracellular vesicles of human adipose tissue-derived mesenchymal stem cells in Alzheimer's disease therapeutics. Methods Mol. Biol. 1212, 171-181. doi: 10.1007/7651_2014_98

Katsuda, T., Tsuchiya, R., Kosaka, N., Yoshioka, Y., Takagaki, K., Oki, K., et al. (2013). Human adipose tissue-derived mesenchymal stem cells secrete functional neprilysin-bound exosomes. Sci. Rep. 3:e53131. doi: 10.1371/ journal.pone.0053131

Keverne, J., and Ray, M. (2005). Neurochemistry of Alzheimer's disease. Psychiatry 4, 40-42. doi: 10.1383/psyt.4.1.40.58307

Kim, D. H., Lee, D., Chang, E. H., Kim, J. H., Hwang, J. W., Kim, J. Y., et al. (2015). GDF-15 secreted from human umbilical cord blood mesenchymal stem cells delivered through the cerebrospinal fluid promotes hippocampal neurogenesis and synaptic activity in an Alzheimer's disease model. Stem Cells Dev. 24, 2378-2390. doi: 10.1089/scd.2014.0487

Kim, S., Kim, D. H., Lee, D., Chang, E. H., Kim, J. H., Hwang, J. W., et al. (2012). The preventive and therapeutic effects of intravenous human adiposederived stem cells in Alzheimer's disease mice. PLoS One 7:e45757. doi: 10.1371/journal.pone.0045757

Klinker, M. W., and Wei, C. H. (2015). Mesenchymal stem cells in the treatment of inflammatory and autoimmune diseases in experimental animal models. World J. Stem Cells 7, 556-567. doi: 10.4252/wjsc.v7.i3.556

Konala, V. B., Mamidi, M. K., Bhonde, R., Das, A. K., Pochampally, R., and Pal, R. (2016). The current landscape of the mesenchymal stromal cell secretome: a new paradigm for cell-free regeneration. Cytotherapy 18, 13-24. doi: 10.1016/j.jcyt.2015.10.008

Koval, L., Lykhmus, O., Zhmak, M., Khruschov, A., Tsetlin, V., Magrini, E., et al. (2011). Differential involvement of $\alpha 4 \beta 2, \alpha 7$ and $\alpha 9 \alpha 10$ nicotinic acetylcholine receptors in B lymphocyte activation in vitro. Int. J. Biochem. Cell Biol. 43, 516-524. doi: 10.1016/j.biocel.2010.12.003

Koval, O. M., Voitenko, L. P., Skok, M. V., Lykhmus, E. Y., Tsetlin, V. I., Zhmak, M. N., et al. (2004). The $\beta$-subunit composition of nicotinic acetylcholine receptors in the neurons of the guinea pig inferior mesenteric ganglion. Neurosci. Lett. 365, 143-146. doi: 10.1016/j.neulet.2004.04.071

Lee, J. K., Jin, H. K., and Bae, J. S. (2009). Bone marrow-derived mesenchymal stem cells reduce brain amyloid-beta deposition and accelerate the activation of microglia in an acutely induced Alzheimer's disease mouse model. Neurosci. Lett. 450, 136-141. doi: 10.1016/j.neulet.2008.11.059

Lee, J. K., Jin, H. K., and Bae, J. S. (2010a). Bone marrow-derived mesenchymal stem cells attenuate amyloid $\beta$-induced memory impairment and apoptosis by inhibiting neuronal cell death. Curr. Alzheimer Res. 7, 540-548.
Lee, J. K., Jin, H. K., Endo, S., Schuchman, E. H., Carter, J. E., and Bae, J. S. (2010b). Intracerebral transplantation of bone marrow-derived mesenchymal stem cells reduces amyloid-beta deposition and rescues memory deficits in Alzheimer's disease mice by modulation of immune responses. Stem Cells 28, 329-343. doi: 10.1002/stem.277

Lee, H. J., Lee, J. K., Lee, H., Carter, J. E., Chang, J. W., Oh, W., et al. (2012). Human umbilical cord blood-derived mesenchymal stem cells improve neuropathology and cognitive impairment in an Alzheimer's disease mouse model through modulation of neuroinflammation. Neurobiol. Aging 33, 588-602. doi: 10.1016/j.neurobiolaging.2010.03.024

Lee, N. K., Yang, J., Chang, E. H., Park, S. E., Lee, J., Choi, S. J., et al. (2016). Intra-arterially delivered mesenchymal stem cells are not detected in the brain parenchyma in an Alzheimer's disease mouse model. PLoS One 11:e0155912. doi: 10.1371/journal.pone.0155912

Lykhmus, O., Gergalova, G., Koval, L., Zhmak, M., Komisarenko, S., and Skok, M. (2014). Mitochondria express several nicotinic acetylcholine receptor subtypes to control various pathways of apoptosis induction. Int. J. Biochem. Cell Biol. 53, 246-252. doi: 10.1016/j.biocel.2014.05.030

Lykhmus, O., Gergalova, G., Zouridakis, M., Tzartos, S., Komisarenko, S., and Skok, M. (2015a). Inflammation decreases the level of alpha 7 nicotinic acetylcholine receptors in the brain mitochondria and makes them more susceptible to apoptosis induction. Int. Immunopharmacol. 29, 148-151. doi: 10.1016/j.infimp.2015.04.007

Lykhmus, O., Koval, L., Pavlovych, S., Zouridakis, M., Zisimopoulou, P., Tzartos, S., et al. (2010). Functional effects of antibodies against nonneuronal nicotinic acetylcholine receptors. Immunol. Lett. 128, 68-73. doi: 10.1016/j.imlet.2009.11.006

Lykhmus, O., Uspenska, K., Koval, L., Lytovchenko, D., Voytenko, L., Horid'ko, T., et al. (2017). N-stearoylethanolamine protects the brain and improves memory of mice treated with lipopolysaccharide or immunized with the extracellular domain of a7 nicotinic acetylcholine receptor. Int. Immunopharmacol. 52, 290-296. doi: 10.1016/j.intimp.2017.09.023

Lykhmus, O., Voytenko, L., Koval, , Mykhalskiy, S., Kholin, V., Peschana, K., et al. (2015b). $\alpha 7$ Nicotinic acetylcholine receptor-specific antibody induces inflammation and amyloid $\beta 42$ accumulation in the mouse brain to impair memory. PLoS One 10:e0122706. doi: 10.1371/journal.pone.0122706

Ma, T., Gong, K., Ao, Q., Yan, Y., Song, B., Huang, H., et al. (2013). Intracerebral transplantation of adipose-derived mesenchymal stem cells alternatively activates microglia and ameliorates neuropathological deficits in Alzheimer's disease mice. Cell Transplant. 22(Suppl. 1), 113-126. doi: $10.3727 / 096368913 \times 672181$

Maslova, O. O., Shuvalova, N. S., Sukhorada, O. M., Zhukova, S. M., Deryabina, O. G., Makarenko, M. V., et al. (2013). Heterogeneity of umbilical cords as a source for mesenchymal stem cells. Dataset Pap. Biol. 1-4. doi: $10.7167 / 2013 / 370103$

Misra, S., Chopra, K., Saikia, U. N., Sinha, V. R., Sehgal, R., Modi, M., et al. (2016). Effect of mesenchymal stem cells and galantamine nanoparticles in rat model of Alzheimer's disease. Regen. Med. 11, 629-646. doi: 10.2217/rme-2016-0032

NIH Stem Cell Information Home Page (2016). Stem cell information [World Wide Website]. Bethesda, MD: National Institutes of Health, U.S. Department of Health and Human Services. Available at: stemcells.nih.gov/info/basics/1.htm

Oh, S. H., Kim, H. N., Park, H. J., Shin, J. Y., and Lee, P. H. (2015). Mesenchymal stem cells increase hippocampal neurogenesis and neuronal differentiation by enhancing the Wnt signaling pathway in an Alzheimer's disease model. Cell Transplant. 24, 1097-10109. doi: 10.3727/096368914X679237

Parada, E., Egea, J., Romero, A., del Barrio, L., García, A. G., and López, M. G. (2010). Poststress treatment with PNU282987 can rescue SH-SY5Y cells undergoing apoptosis via a7 nicotinic receptors linked to a Jak2/Akt/HO-1 signaling pathway. Free Radic. Biol. Med. 49, 1815-1821. doi: 10.1016/j. freeradbiomed.2010.09.017

Park, S. E., Lee, J., Chang, E. H., Kim, J. H., Sung, J. H., Na, D. L., et al. (2016). Activin A secreted by human mesenchymal stem cells induces neuronal development and neurite outgrowth in an in vitro model of Alzheimer's disease: neurogenesis induced by MSCs via activin A. Arch. Pharm. Res. 39, 1171-1179. doi: 10.1007/s12272-016-0799-4

Parri, H. R., and Dineley, K. T. (2010). Nicotinic acetylcholine receptor interaction with $\beta$-amyloid: molecular, cellular, and physiological consequences. Curr. Alzheimer Res. 7, 27-39. doi: 10.2174/156720510790274464 
Paxinos, G., and Franklin, K. B. J. (2001). The mouse brain in stereotaxic coordinates. (New York: Academic Press).

Picciotto, M. R., Caldarone, B. J., Brunzell, D. H., Zachariou, V., Stevens, T. R., and King, S. L. (2001). Neuronal nicotinic acetylcholine receptor subunit knockout mice: physiological and behavioral phenotypes and possible clinical implications. Pharmacol. Ther. 92, 89-108. doi: 10.1016/S0163-7258(01)00161-9

Posadas, I., López-Hernández, B., and Ceña, V. (2013). Nicotinic receptors in neurodegeneration. Curr. Neuropharmacol. 11, 298-314. doi: 10.2174/1570159X11311030005

Russo, P., Del Bufalo, A., Frustaci, A., Fini, M., and Cesario, A. (2014). Beyond acetylcholinesterase inhibitors for treating Alzheimer's disease: $\alpha 7-n A C h R$ agonists in human clinical trials. Curr. Pharm. Res. 20, 6014-6021.

Rüster, B. R., Göttig, S., Ludwig, R. J., Bistrian, R., Müller, S., and Seifried, E. (2006). Mesenchymal stem cells display coordinated rolling and adhesion behavior on endothelial cells. Blood 108, 3938-3944. doi: 10.1182/ blood-2006-05-025098

Salem, A. M., Ahmed, H. H., Atta, H. M., Ghazy, M. A., and Aglan, H. A. (2014). Potential of bone marrow mesenchymal stem cells in management of Alzheimer's disease in female rats. Cell Biol. Int. 38, 1367-1383. doi: 10.1002/cbin.10331

Save, E., Poucet, B., Foreman, N., and Buhot, M.-C. (1992). Object exploration and reactions to spatial and nonspatial changes in hooded rats following damage to parietal cortex or hippocampal formation. Behav. Neurosci. 106, 447-456. doi: 10.1037/0735-7044.106.3.447

Shin, J. Y., Park, H. J., Kim, H. N., Oh, S. H., Bae, J. S., Ha, H. J., et al. (2014). Mesenchymal stem cells enhance autophagy and increase $\beta$-amyloid clearance in Alzheimer disease models. Autophagy 10, 32-44. doi: 10.4161/ auto. 26508

Shuvalova, N. S., and Kordium, V. A. (2016). Morphological characteristics of mesenchymal stem cells from Wharton jelly, cultivated under physiological oxygen tensions, in various gas mixtures. Biopolym. Cell 32, 262-270. doi: 10.7124/bc.000928

Shuvalova, N. S., Maslova, O. A., Sukhorada, O. M., Deryabina, O. G., and Kordium, V. A. (2013). Maintenance of mesenchymal stem cells culture due to the cells with reduced attachment rate. Biopolym. Cell 29, 75-78. doi: 10.7124/bc000809

Skok, M., and Lykhmus, O. (2016). The role of a7 nicotinic acetylcholine receptors and $\alpha 7$-specific antibodies in neuroinflammation related to Alzheimer disease. Curr. Pharm. Des. 22, 2035-2049.

Skok, M. V., Voitenko, L. P., Voitenko, S. V., Lykhmus, E. Y., Kalashnik, E. N., Litvin, T. I., et al. (1999). Alpha subunit composition of nicotinic acetylcholine receptors in the rat autonomic ganglia neurons as determined with subunitspecific anti-alpha(181-192) peptide antibodies. Neuroscience 93, 1427-1436. doi: 10.1016/S0306-4522(99)00160-8

Suzuki, T., Hide, I., Matsubara, A., Hama, C., Harada, K., Miyano, K., et al. (2006). Microglial alpha7 nicotinic acetylcholine receptors drive a phospholipase C/IP3 pathway and modulate the cell activation toward a neuroprotective role. J. Neurosci. Res. 83, 1461-1470. doi: 10.1002/jnr20850

Thinus-Blanc, C. (1996). Animal spatial cognition. Behavioral and neural approaches. (Singapore, New Jersey, London, Hong Kong: World Scientific Publishing Co).

Thomsen, M. S., and Mikkelsen, J. D. (2012). Thea7 nicotinic acetylcholine receptor ligands methyllycaconitine, NS6740 and GTS-21 reduce lipopolysaccharideinduced TNF- $\alpha$ release from microglia. J. Neuroimmunol. 251, 65-72. doi: 10.1016/jneuroim.2012.07.006

Toropova, A. P., Toropov, A. A., Begum, S., and Achary, P. G. R. (2018). Blood brain barrier and Alzheimer's disease: similarity and dissimilarity of molecular alerts. Curr. Neuropharmacol. 16, 769-785. doi: 10.2174/157015 9X15666171016163951
Tyagi, E., Agrawal, R., Nath, C., and Shukla, R. (2010). Cholinergic protection via alpha7 nicotinic acetylcholine receptors and PI3K-Akt pathway in LPSinduced neuroinflammation. Neurochem. Int. 56, 135-142. doi: 10.1016/j. neuint.2009.09.011

Uspenska, K., Lykhmus, O., Gergalova, G., Chernyshov, V., Arias, H. R., Komisarenko, S., et al. (2017). Nicotine facilitates nicotinic acetylcholine receptor targeting to mitochondria but makes them less susceptible to selective ligands. Neurosci. Lett. 656, 43-50. doi: 10.1016/j.neulet.2017.07.009

Uspenska, K., Lykhmus, O., Obolenskaya, M., Pons, S., Maskos, U., Komisarenko, S., et al. (2018). Mitochondrial nicotinic acetylcholine receptors support liver cells viability after partial hepatectomy. Front. Pharmacol. 9:626. doi: 10.3389/ fphar.2018.00626

Wagner, J. A. (1996). Is IL-6 both a cytokine and a neurotrophic factor? J. Exp. Med. 183, 2417-2419. doi: 10.1084/jem.183.6.2417

Wang, H. Y., Lee, D. H., D’Andrea, M. R., Peterson, P. A., Shank, R. P., and Reitz, A. B. (2000). $\beta$-Amyloid $1-42$ binds to $\alpha 7$ nicotinic acetylcholine receptor with high affinity. Implications for Alzheimer's disease pathology. J. Biol. Chem. 275, 5626-5632. doi: 10.1074/jbc.275.8.5626

Wevers, A., Monteggia, L., Nowacki, S., Bloch, W., Schütz, U., Lindstrom, J., et al. (1999). Expression of nicotinic acetylcholine receptor subunits in the cerebral cortex in Alzheimer's disease: histotopographical correlation with amyloid plaques and hyperphosphorylated-tau protein. Eur. J. Neurosci. 11, 2551-2565. doi: 10.1046/j.1460-9568.1999.00676.x

Yan, Y., Ma, T., Gong, K., Ao, Q., Zhang, X., and Gong, Y. (2014). Adiposederived mesenchymalstemcell transplantation promotes adult neurogenesis in the brains of Alzheimer's disease mice. Neural Regen. Res. 9, 798-805. doi: 10.4103/1673-5374.131596

Yang, H., Xie, Z., Wei, L., Yang, H., Yang, S., Zhu, Z., et al. (2013). Human umbilical cord mesenchymalstemcell-derived neuron-like cells rescue memory deficits and reduce amyloid-beta deposition in an A $\beta P P / P S 1$ transgenic mouse model. Stem Cell Res. Ther. 4:76. doi: 10.1186/scrt227

Zachar, L., Bačenková, D., and Rosocha, J. (2016). Activation, homing, and role of the mesenchymal stem cells in the inflammatory environment. J. Inflamm. Res. 9, 231-240. doi: 10.2147/JIR.S121994

Zenaro, E., Piacentino, G., and Constantin, G. (2017). The blood-brain barrier in Alzheimer's disease. Neurobiol. Dis. 107, 1-56. doi: 10.3389/fimmu.2017.00211

Zhang, P., Zhao, G., Kang, X., and Su, L. (2012). Effects of lateral ventricular transplantation of bone marrow-derived mesenchymal stem cells modified with brain-derived neurotrophic factor gene on cognition in a rat model of Alzheimer's disease. Neural Regen. Res. 7, 245-250. doi: 10.3969/j. issn.1673-5374.2012.04.001

Zlokovic, B. V. (2008). The blood-brain barrier in health and chronic neurodegenerative disorders. Neuron 57, 178-201. doi: 10.1016/j. neuron.2008.01.003

Zoli, M., Picciotto, M. R., Ferrari, R., Cocchi, D., and Changeux, J. P. (1999). Increased neurodegeneration during ageing in mice lacking high-affinity nicotine receptors. EMBO J. 18, 1235-1244. doi: 10.1093/emboj/18.5.1235

Conflict of Interest Statement: The authors declare that the research was conducted in the absence of any commercial or financial relationships that could be construed as a potential conflict of interest.

Copyright (C) 2019 Lykhmus, Koval, Voytenko, Uspenska, Komisarenko, Deryabina, Shuvalova, Kordium, Ustymenko, Kyryk and Skok. This is an open-access article distributed under the terms of the Creative Commons Attribution License (CC BY). The use, distribution or reproduction in other forums is permitted, provided the original author(s) and the copyright owner(s) are credited and that the original publication in this journal is cited, in accordance with accepted academic practice. No use, distribution or reproduction is permitted which does not comply with these terms. 